\title{
Compression Behavior of Mg-Cu-Gd Bulk Metallic Glasses with Various Specimen Height to Diameter Ratios
}

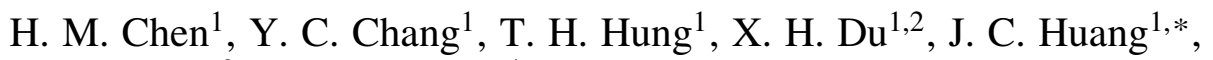 \\ J. S. C. Jang ${ }^{3}$ and P. K. Liaw ${ }^{4}$ \\ ${ }^{1}$ Institute of Materials Sci. \& Eng.; Center for Nanoscience and Nanotechnology, \\ National Sun Yat-Sen University, Kaohsiung, Taiwan 804, R.O. China \\ ${ }^{2}$ Department of Materials Engineering, Shenyang Institute of Aeronautical Engineering, Shenyang, 110034, P.R. China \\ ${ }^{3}$ Department of Materials Sci. \& Eng., I-Shou University, Kaohsiung, Taiwan 840, R.O. China \\ ${ }^{4}$ Department of Materials Sci. \& Eng., University of Tennessee, Knoxville, TN 37996-2200, USA
}

\begin{abstract}
The mechanical behavior of the $\mathrm{Mg}_{65} \mathrm{Cu}_{25} \mathrm{Gd}_{10}$ bulk metallic glasses (BMGs) in term of compression testing is reported in this study. Room-temperature compression tests are conducted on specimens with various height to diameter ratios $(h / d)$ from $2: 1,1: 1,1: 2$, to $1: 4$. The failure strength, deformation strain, and the fracture surface morphologies are seen to vary systematically in accordance with the specimen $h / d$ ratio. For specimens with $h / d$ of $2: 1$ or $1: 1$, the compression response is similar to those in most reports. In contrast, for specimens with lower $h / d$ ratios, especially at $h / d=1: 4$ (or 0.25 ), the shear band propagation appears to be constrained, resulting in the enhanced ductility. It suggests that different deformation mechanisms are operative for specimens with different $h / d$ ratios. The possible deformation mechanisms in specimens of different geometries are discussed. [doi:10.2320/matertrans.MJ200722]
\end{abstract}

(Received November 14, 2006; Accepted February 13, 2007; Published June 20, 2007)

Keywords: metallic glasses, mechanical properties, shear bands, deformation mechanisms, brittleness and ductility

\section{Introduction}

Bulk metallic glasses have unique mechanical and physical properties, such as high strength and hardness, high elastic modulus, excellent corrosion resistance, and electromagnetic properties, ${ }^{1)}$ attributed to the atomic structure of the amorphous phase. From the industrial needs in developing high-strength materials with light weight, Mg-based alloys have attracted great interests due to the lowest specific weight among all structural metallic materials. Hence, the Mg-based bulk metallic glasses (BMG) are regarded as a new family of promising materials with excellent specific strength and good corrosion resistance. ${ }^{2)}$ Recently, new Mg-based amorphous alloys with a high glass forming ability (GFA) have been developed in a number of alloy systems, such as Mg-TM-RE $(\mathrm{TM}=$ transition metal such as $\mathrm{Cu}$ or $\mathrm{Ag}$ and $\mathrm{RE}=$ rareearth metal, such as $\mathrm{Gd}$ or $\mathrm{Nd}$, including Y). ${ }^{3-5}$ So far, the development of the Mg-based amorphous alloys has been successfully progressed into bulk sizes larger than ten millimeters. ${ }^{5)}$

It is well known that the crystalline alloy is subjected to elastic deformation, followed by yielding, plastic deformation, and then final fracture. In contrast, it is recognized that the stress-strain curve of an amorphous alloy frequently lacks the sufficient plastic deformation. The defect-free BMG specimens exhibit different mechanical properties as compared with their crystalline counterparts. Generally, the mechanical responses of the Mg-based BMGs at room temperature exhibit a high strength over $600 \mathrm{MPa}$, significantly higher than the $\sim 300 \mathrm{MPa}$ for the commercial $\mathrm{Mg}$ crystalline alloys. At room temperature, the Mg-based BMGs fracture in a very brittle manner with almost no plastic deformation, suggesting that the poor ductility and subsequent catastrophic fracture severely limit their processing

*Corresponding author, E-mail: jacobc@mail.nsysu.edu.tw and application.

Lately, worldwide researches have been proposed to improve the BMG ductility. ${ }^{6-8)}$ Schroers et al. ${ }^{6)}$ performed bending tests on the $\mathrm{Pt}_{57.5} \mathrm{Cu}_{14.7} \mathrm{Ni}_{5.3} \mathrm{P}_{22.5}$ BMG using bar specimens with different thicknesses. The specimen with the thickness of $1.8 \mathrm{~mm}$ did not fracture during bending, showing a maximum strain of $15.7 \%$. However, the strain to fracture of the specimen with the thickness of $4 \mathrm{~mm}$ was only $3 \%$. Also, as proposed by Conner et al. ${ }^{9)}$ metallic glass specimens with an height (h) to diameter (d) ratio, $h / d$, of a round rod specimen less than $1.5: 1$ could usually deform in an elasticperfectly plastic manner caused by geometrical constraints on shear band propagation under compression tests, while those with aspect ratios in excess of $1.5: 1$ show little or no plastic deformation. Moreover, Jiang et al. ${ }^{10)}$ conducted the compression tests on the specimens with different $h / d$ ratios for $\mathrm{Zr}_{52.5} \mathrm{Cu}_{17.9} \mathrm{Ni}_{14.6} \mathrm{Al}_{10.0} \mathrm{Ti}_{5.0}$. The plasticity reached almost $80 \%$ for the specimens with the $h / d$ ratio of 0.5 , which is much higher than the $2 \%$ plasticity for the specimens with the $h / d$ ratio of 2 . They attributed the difference to the specimen geometry effect where the platen can hinder the excessive propagation of shear bands from the premature fracture.

Since the Mg based BMGs have a low Poison ratio around 0.3 , and thus intrinsically brittle nature, the improvements of their ductility and toughness by means of the alloy design, secondary crystallization, or insertion of ductile metal particles are all under studies. If the specimen geometry and shape can affect the ductility much, then the engineering structural applications of Mg BMGs may be oriented to thinsheet specimens, or even focused for thick film-coating applications. The major applied load may be designed to be compression rather than tension. Thus, the current study explores the compression response of the $\mathrm{Mg}-\mathrm{Cu}-\mathrm{Gd}$ BMGs with various $h / d$ ratios. The deformation behaviors are discussed systematically. 
Table 1 Thermal properties of the $\mathrm{Mg}_{65} \mathrm{Cu}_{25} \mathrm{Gd}_{10}$ BMGs obtained from DSC.

\begin{tabular}{cccccccccc}
\hline $\begin{array}{c}\text { Heating rate } \\
(\mathrm{K} / \mathrm{s})\end{array}$ & $\begin{array}{c}T_{\mathrm{g}} \\
(\mathrm{K})\end{array}$ & $\begin{array}{c}T_{\mathrm{x}} \\
(\mathrm{K})\end{array}$ & $\begin{array}{c}\Delta T_{\mathrm{x}} \\
(\mathrm{K})\end{array}$ & $\begin{array}{c}T_{\mathrm{m}} \\
(\mathrm{K})\end{array}$ & $\begin{array}{c}T_{l} \\
(\mathrm{~K})\end{array}$ & $\begin{array}{c}\Delta T_{l} \\
(\mathrm{~K})\end{array}$ & $T_{\mathrm{rg}}$ & $\gamma$ & $\phi$ \\
\hline 0.33 & 414 & 482 & 68 & 681 & 727 & 46 & 0.569 & 0.422 & 0.439 \\
0.67 & 421 & 490 & 69 & 684 & 738 & 54 & 0.570 & 0.423 & 0.440 \\
\hline
\end{tabular}

\section{Experimental Procedure}

The multicomponent alloys with the designed compositions of $\mathrm{Mg}_{65} \mathrm{Cu}_{25} \mathrm{Gd}_{10}$ are examined in this work. The master alloys were prepared by arc melting of $\mathrm{Cu}$ and $\mathrm{Gd}$ (purity: $\mathrm{Cu}=99.99 \%$ and $\mathrm{Gd}=99.9 \%$ ) under an argon atmosphere. Then the master alloys were melted with $\mathrm{Mg}$ (99.9\%) in an iron crucible using induction melting. After complete melting, the alloys were poured into a water-cooled copper mold in an argon atmosphere. The $\mathrm{Mg}-\mathrm{Cu}-\mathrm{Gd}$ master alloys were fabricated by re-melting the appropriate amount of the alloy in a quartz tube under an argon atmosphere, followed by injection casting into a water-cooled copper mold with internal cylindrical-shaped cavities of $4 \mathrm{~mm}$ in diameter. The alloy composition was analyzed by the scanning electron microscopy (SEM) linked with an energy dispersive X-ray spectrometry (EDS). Furthermore, the amorphous nature was examined by the X-ray diffraction (XRD) and the differential scanning calorimetry (DSC) with the heating rates of 0.33 and $0.67 \mathrm{~K} / \mathrm{s}$. Room temperature compression tests were conducted on rod or disc specimens with various $h / d$ ratios from $2,1,0.5$ to $0.25(4 \mathrm{~mm}$ in diameter with a specimen thickness of $8,4,2$, and $1 \mathrm{~mm}$, respectively) by an Instron 5582 universal testing machine. All specimens need to be ground and polished properly. Before the specimen was fixed into the platens, made of hard tool steel, under the Instron machine, the BN was used as lubricant so as to decrease the friction between the specimen and platens. Afterward the specimen was compressed between the hard BN platens under a displacement control corresponding to a strain rate of $5 \times 10^{-4} \mathrm{~s}^{-1}$. Two WC coating layers were applied for the upper and lower platen surfaces facing the loaded specimen. Finally, the fracture surface morphologies of the deformed specimens were observed by SEM.

\section{Results and Discussion}

All injection-cast BMG rods measuring $4 \mathrm{~mm}$ in diameter are confirmed first that the alloy composition matches the designed composition by EDS and identified as a glassy structure with a broad and diffuse diffraction peak. Furthermore, the thermal properties of the $\mathrm{Mg}_{65} \mathrm{Cu}_{25} \mathrm{Gd}_{10}$ BMG rod are extracted from DSC with the different heating rates of 0.33 and $0.67 \mathrm{~K} / \mathrm{s}$, as summarized in Table 1 . On the basis of DSC analyses, the supercooled temperature range, $\Delta T_{\mathrm{x}}$, the liquidus and solidus temperature range, $\Delta T_{l}, T_{\mathrm{rg}}\left(=T_{\mathrm{g}} / T_{l}\right.$, where $T_{\mathrm{g}}$ and $T_{l}$ are the glass transition and liquidus temperatures), $\gamma\left(=T_{\mathrm{x}} /\left(T_{\mathrm{g}}+T_{l}\right)\right.$, where $T_{\mathrm{x}}$ is the crystallization temperature $),{ }^{11)}$ and $\phi\left(=T_{\mathrm{rg}}\left(\Delta T_{\mathrm{x}} / T_{\mathrm{g}}\right)^{0.143}\right)^{12)}$ are $69 \mathrm{~K}, 54 \mathrm{~K}, 0.570,0.423$ and 0.440 for $\mathrm{Mg}_{65} \mathrm{Cu}_{25} \mathrm{Gd}_{10}$ at a heating rate of $0.67 \mathrm{~K} / \mathrm{s}$, respectively. It indicates that the

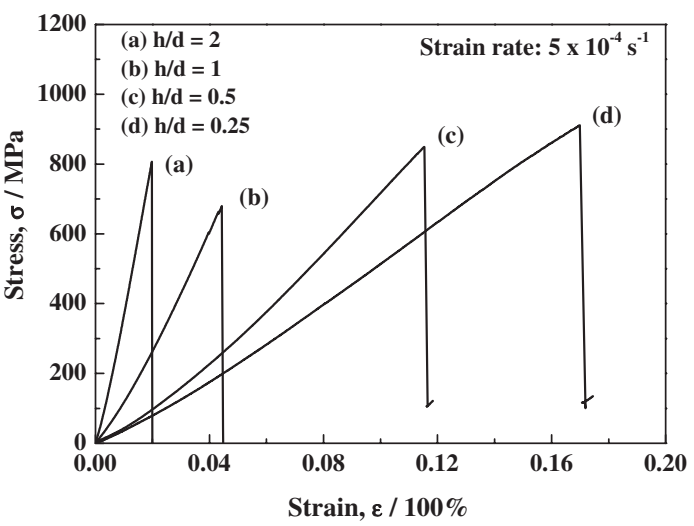

Fig. 1 Room temperature engineering stress-strain curves of the $\mathrm{Mg}_{65} \mathrm{Cu}_{25} \mathrm{Gd}_{10}$ specimens with various $h / d$ ratios from 2 to 0.25 at a strain rate of $5 \times 10^{-4} \mathrm{~s}^{-1}$.

$\mathrm{Mg}_{65} \mathrm{Cu}_{25} \mathrm{Gd}_{10}$ BMG exhibits a sufficiently wide supercooled liquid region and high GFA.

Figure 1 shows the engineering stress-strain curves of the specimens with various $h / d$ ratios from 2 to 0.25 for $\mathrm{Mg}_{65} \mathrm{Cu}_{25} \mathrm{Gd}_{10}$ under compression testing at a strain rate of $5 \times 10^{-4} \mathrm{~s}^{-1}$. First of all, it can be found that the failure strength, deformation strain, and the observed slope are seen to vary for specimens with various $h / d$ ratios. The fracture stress and strain are $\sim 806 \mathrm{MPa}$ and $\sim 2 \%$ for the specimen with $h / d=2$. For specimens with $h / d=2$ or 1 , the compression responses are basically similar to most reported $\mathrm{Mg}$ based BMGs, exhibiting the brittle nature with no evidence of the macroscopic yielding and plasticity. In contrast, for specimens with a lower $h / d$ ratio $(=0.5$ or 0.25 ), the engineering stress-strain curves seem to reveal a higher degree of ductility than the specimens with an $h / d$ ratio greater than 1 . Especially for $h / d=0.25$, the fracture stress and strain are as high as $\sim 911 \mathrm{MPa}$ and $\sim 17 \%$, respectively, suggesting that it is characterized by an excellent ductility. The original disc specimen thickness was $1 \mathrm{~mm}$, and the final thickness of the failed but still intact specimen became $\sim 0.85 \mathrm{~mm}$. To confirm the trend, separate Mg based BMG specimens, with slightly different compositions and diameters but with an $h / d$ ratio of $1: 5$ (or 0.2 ), reveal an even higher strength and strain of over $1,000 \mathrm{MPa}$ and over 35\%. It is ensured that the trend observed in Fig. 1 can be reputable. The compression properties of the specimens with various $h / d$ ratios for $\mathrm{Mg}_{65} \mathrm{Cu}_{25} \mathrm{Gd}_{10}$ are summarized in Table 2.

The slope of the specimen with $h / d=2$ is around $50 \mathrm{GPa}$, which is close to the elastic modulus reported for most $\mathrm{Mg}$ based BMGs and is similar to the value measured by the nano-indentation on the same specimen. ${ }^{13)}$ However, the slope is seen to decline with decreasing $h / d$ ratio, falling to $\sim 6 \mathrm{GPa}$ for the disc specimen with $h / d=0.25$. It is parent that this slope does not correspond to the real elastic modulus, the specimen does not follow the compression test requirements set by American Society for Testing and Materials (ASTM), and the geometry shape affects the response slope.

The fracture-surface morphologies of the compressed $\mathrm{Mg}_{65} \mathrm{Cu}_{25} \mathrm{Gd}_{10}$ are characterized by SEM. Figure 2 shows 
Table 2 Compressive properties of the $\mathrm{Mg}_{65} \mathrm{Cu}_{25} \mathrm{Gd}_{10}$ specimens with various $h / d$ ratios.

\begin{tabular}{ccccc}
\hline $\begin{array}{c}\text { Strain rate } \\
\left(\mathrm{s}^{-1}\right)\end{array}$ & $h / d$ ratio & $\begin{array}{c}\text { Apparent modulus } \\
(\mathrm{GPa})\end{array}$ & $\begin{array}{c}\text { Stress } \\
(\mathrm{MPa})\end{array}$ & $\begin{array}{c}\text { Strain } \\
(\%)\end{array}$ \\
\hline & 2 & $\sim 50$ & 806 & 1.97 \\
$5 \times 10^{-4}$ & 1 & $\sim 21$ & 679 & 4.15 \\
& 0.5 & $\sim 9$ & 848 & 11.53 \\
& 0.25 & $\sim 6$ & 911 & 16.99 \\
\hline
\end{tabular}

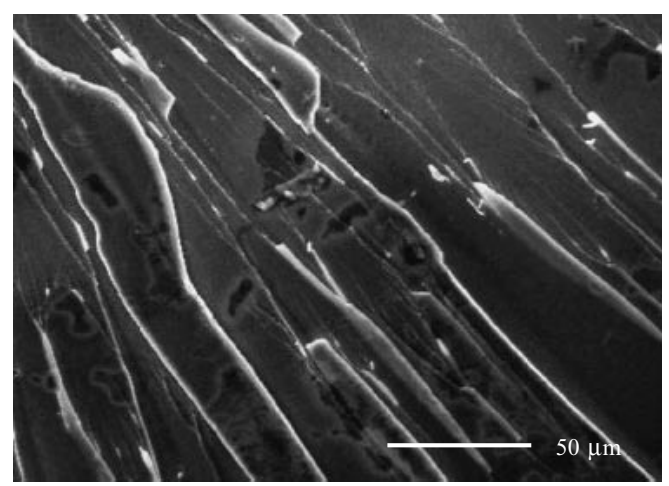

Fig. 2 Fracture surface morphology of the $\mathrm{Mg}_{65} \mathrm{Cu}_{25} \mathrm{Gd}_{10}$ specimen with a $h / d$ ratio of 2 .

that the fracture-surface morphology for specimens with $h / d=2$ exhibits the cleavage feature resulted from the brittle fracture nature without the observable vein-like structures. Nevertheless, for specimen with $h / d=0.25$, the compressed specimen is still intact without a catastrophic fracture into pieces, as would be for the rod specimens with $h / d=2$. Figure 3 shows that the fracture-surface morphology for specimens with $h / d=0.25$. It is found that there are highly dense vein-like structures spreading over the whole fracture surface. The vein structures are complicated and contain multiple variants. Some vein-like structures appear to have suffered a drastic deformation, implying that the shear band propagation have been intense and complicated. It is evident that the initial shear bands induced during the early stage of compression were stopped by the upper and bottom platens, and subsequent variants of shear bands are continuously induced and propagate throughout the specimens. By closer examinations of the enlarged view of the engineering stressstrain curve for the specimen with $h / d=0.25$, as shown in Fig. 4, there are numerous serrated flow phenomena as marked by circles. It is clear that successive generation and propagation of multiple shear bands were undertaken. If the specimen is loaded under tension, the load drop will be more pronounced. But under compression, the continuous compressive deformation will lead to a continuous stress increment; the serration due to the local shear banding will be mostly shadowed. Without close examinations, one might consider the large strain to be a result of elastic straining. In fact, the large strain of $17 \%$ is basically contributed by the plastic deformation of successive shear banding. That is why the final specimen thickness was found to be reduced by $\sim 15 \%$.

There are some other factors involved in the compression testing, especially for the significant enhancement of com-

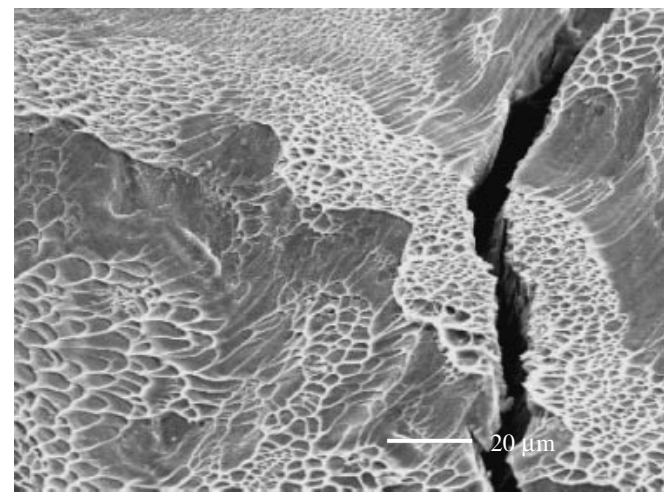

Fig. 3 Fracture surface morphology of the $\mathrm{Mg}_{65} \mathrm{Cu}_{25} \mathrm{Gd}_{10}$ specimen with a $h / d$ ratio of 0.25

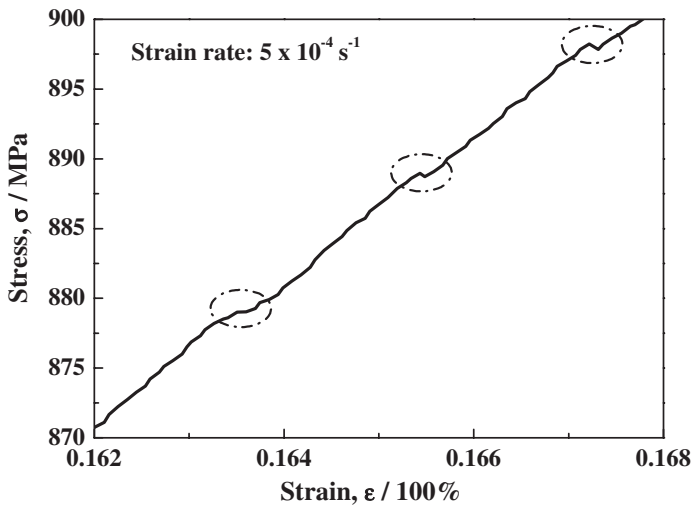

Fig. 4 Enlarged view of the compressive stress-strain curve of the $\mathrm{Mg}_{65} \mathrm{Cu}_{25} \mathrm{Gd}_{10}$ specimen with $h / d=0.25$ at a strain rate of $5 \times$ $10^{-4} \mathrm{~s}^{-1}$, showing the serrated flow phenomenon.

pression strain to $17 \%$ and the apparent reduced modulus from the recorded stress-strain curve for the specimen with $h / d$ ratio $=0.5$ or 0.25 . Firstly, the hydrostatic stress for specimens with various $h / d$ ratios will be different because the free surface portion (without contacting the dies or platens) for thin specimens (e.g., $h / d=0.25)$ is much lower than the long rod (e.g., $h / d=2)$. Thus, it will result in a much higher average hydrostatic stress imposed on the thin specimens. As proposed by Lowhaphandu et al. ${ }^{14)}$ the superimposed hydrostatic stress on the flow/fracture stress and fracture strain for $\mathrm{Zr}$ based BMGs exhibits some effects. Moreover, as proposed by Vaidyanathan et al., ${ }^{15)}$ the deformation characteristics of metallic glasses vary in many respects. Metallic glasses do not reveal any strain hardening and the available experimental results strongly imply that the mechanical response of BMG is influenced by the shear and the normal component of the local stress, as well as the hydrostatic stress. It is known that the hydrostatic stress will increase the allowed displacement. Hence, the higher displacement will decrease the observed slope. Secondly, the actual temperature for specimens with various $h / d$ ratios will also be different. The generated heat will be more difficult to release for thin specimens, indicating the trapped heat will raise more the specimen temperature. Thirdly, the constraint caused by the upper and bottom platens will drastically increase the number of shear-band occurrences. The overall 
accumulated heat or stored deformation energy will be much higher for thin specimens. With a higher specimen temperature, the modulus will proportionally be lowered accordingly.

During room temperature compression tests, the Pd-based and Zr-based BMGs with normal $h / d$ ratio of $\sim 2$ typically demonstrate a pure shear fracture process with a certain level of plasticity of $5 \%$ or above. The limited compressive plasticity is caused by localized shear bands and is characterized by the serrated plastic flow. The compressive fracture morphology commonly exhibits the vein-like structures spreading over the whole surfaces along the propagation of the shear band and the fracture angle is normally closed to $45^{\circ}{ }^{16)}$ For compression on the $\mathrm{Pt}$ or $\mathrm{Zr}$ based BMGs with a low $h / d$ ratio less than 1 , a compression strain greater than $30 \%$ can be achieved. ${ }^{9,10)}$ However, the compression response of the current brittle $\mathrm{Mg}$ based BMGs with a smaller Poisson's ratio is different from the tougher $\mathrm{Pt}$ or $\mathrm{Zr}$ based BMGs with larger Poisson's ratios. Since the specimen is as thin as a sheet, the specimen will always be constrained during compression testing. The brittle $\mathrm{Mg}$ BMG specimen with $h / d=0.5$ or 0.25 might have been failed or locally fractured. However, the fractured but still intact pieces could be further fused during the subsequent deformation when secondary shear bands are induced and propagate.

With the fact that the specimen geometry would influence the shear band initiation and propagation, as well as the mechanical responses of the metallic glasses, the practical users can utilize the advantage of enhanced ductility for thin metallic glass materials. The Mg based BMGs might have difficulty for wide structural applications owing to their intrinsic brittle nature. The light $\mathrm{Mg}$ BMGs do not seem to be suitable to be used as sport goods or transport vehicles, but their light weight and shinning surface might be practical for thin sheet panels or enclosures. They are also perfect for surface thick-film coatings to improve the surface hardness and wear resistance. In addition, they might be applied for small scale systems such as thin discs for micromachines or micro electromechancal systems (MEMS). All of the latter usages as thin sheets or film coatings are expected to be subject to compression loading rather than tension or bending. The enhanced ductility favors applications along these lines.

\section{Conclusion}

Compression properties and fracture morphologies for $\mathrm{Mg}_{65} \mathrm{Cu}_{25} \mathrm{Gd}_{10}$ BMGs were examined for rod or disc specimens with different $h / d$ ratios from $2: 1$ down to $1: 4$. For specimens with higher $h / d$ ratios, the compression responses are similar to most reports for the Mg based BMGs, with a room temperature compression strength of $\sim 800 \mathrm{MPa}$ and strain of $\sim 2 \%$. In contrast, for specimens with lower $h / d$ ratios, especially at $h / d=0.25$, the shear band propagation appears to be constrained by the upper and bottom platens. The thin disc specimens would undergo extended compression straining with the pronounced multiple shear banding generation and propagation, resulting in a higher strength of $\sim 900 \mathrm{MPa}$ and strain of $17 \%$. The underlying reasons and factors involved for such specimen geometry effects are discussed and rationalized. Finally, the shape effect for the brittle $\mathrm{Mg}$ based glasses can be utilized for applications as thin sheets, film coating, or mini MEMS pieces where the compression loading, rather than tension or bending loading, is of more concern.

\section{Acknowledgements}

The authors would like to gratefully acknowledge the sponsorship from (1) National Science Council of Taiwan, ROC, under the project number of NSC94-2216-E110-010, and (2) the US National Science Foundation Program International Materials Institutes (IMI) under the contrast number of DMR-0231320, with Dr. C. Huber as the Program Director.

\section{REFERENCES}

1) A. Inoue: Mater. Sci. Eng. A 304-306 (2001) 1-10.

2) N. H. Pryds: Mater. Sci. Eng. A 375-377 (2004) 186-193.

3) H. Men and D. H. Kim: J. Mater. Res. 18 (2003) 1502-1504.

4) E. S. Park, H. G. Kang, W. T. Kim and D. H. Kim: J. Non-Cryst. Solids 279 (2001) 154-160.

5) Q. Zheng, H. Ma, E. Ma and J. Xu: Scripta Mater. 55 (2006) 541-544.

6) J. Schroers and W. L. Johnson: Phys. Rev. Lett. 93 (2004) 255506.

7) C. Fan, L. J. Kecskes, D. C. Qiao, H. Choo and P. K. Liaw: J. NonCryst. Solids 352 (2006) 174-179.

8) F. X. Liu, P. K. Liaw, G. Y. Wang, C. L. Chiang, D. A. Smith, P. D. Pack, J. P. Chu and R. A. Buchanan: Intermetallics 14 (2006) 10141018.

9) R. D. Conner, Y. Li, W. D. Nix and W. L. Jonson: Acta Mater. 52 (2004) 2429-2434.

10) W. H. Jiang, G. J. Fan, H. Choo and P. K. Liaw: Mater. Lett. 60 (2006) 3537-3540.

11) Z. P. Lu and C. T. Liu: Acta Mater. 50 (2002) 3501-3512.

12) G. J. Fan, H. Choo and P. K. Liaw: J. Non-Cryst. Solids 353 (2007) $102-107$.

13) T. H. Hung, Y. C. Chang, H. M. Chen, Y. L. Tsai, J. C. Huang, J. S. C. Jang and T. G. Nieh: Mater. Sci. Forum. 539-543 (2007) 1926-1931.

14) P. Lowhaphandu, S. L. Montgomery and J. J. Lewandowski: Scripta Mater. 41 (1999) 19-24.

15) R. Vaidyanathan, M. Dao, G. Ravichandarn and S. Suresh: Acta Mater. 49 (2001) 3781-3789.

16) G. F. Zhang, J. Eckert and J. Schultz: Acta Mater. 51 (2003) 11671179 . 